\title{
Research on Several Questions about Engineering Education Center
}

\author{
X.T. ZHOU, X.XIAO \\ Guangdong University of Petrochemical Technology, Maoming, Guangdong, China
}

\begin{abstract}
Engineering education and engineering practice is relationship of premises each other. To train reserve personnel for meeting the requirements of engineering, engineering education must return to engineering. Therefore, it is particularly important to construct engineering education center well, which creates engineering practice condition and real engineering environment for students. Discussions will be done about the classification, properties, functions, construction, management and the significance for improving the quality of engineering education.
\end{abstract}

KEYWORD: Engineering education; Center of engineering education; Research

\section{INTRODUCTION}

According to the Wikipedia, engineering education is the activity of teaching knowledge and principles related to the professional practice of engineering. It includes the initial education for becoming an engineer and any advanced education and specializations that follow. Engineering education is typically accompanied by additional examinations and supervised training as the requirements for a professional engineering license [1]. From above we can see that to train engineers is the main task of engineering education. And engineering education must grow up with the development of industry. Cui Jun[2] thinks that a large deviation has appeared in China's engineering education in the past few years, which mainly displays in the course objective is far away from the industrial demand, the course structure is separated with engineering ability, and the course content deviates from engineering practice, and the consciousness of industrial civilization is not popular enough. It showed that engineering education must return to the project.

Because of the progress of technology, combined with the strict requirements in cost, quality, environment and security, as well as the process of modern industrial production has been continuous, automatic and in scale, some have been enclosed fully. So for engineering education it is impossible to perform engineering practice at the scene of the production, and center of engineering education arises at the moment, the main contents of which are: 1) a team of guidance teachers with rich experiences in engineering practice, combined full-time and parttime; 2) a set of effective measures for the management of engineering practical education; 3) a batch of experimental equipment of nice operability and practical functions, or a group of modified equipment retired from factories; 4) a set of computer simulation system. This is, in today's world, the important means and forms of engineering practical training.

As the function and venue of engineering education center, it can be divided into campus and off-campus one and, in China, the latter is also called practical education base for students based on enterprises. Such bases, constructed in line with the implementation of the education 'outstanding engineers training plan', are called engineering practical education center.

According to 'Notice About The Construction Of National Engineering Practice Education Center From China Ministry Of Education' [3], combined with experiences from our college accumulated during the construction of center engineering practical education, a discussion about the center's classification, properties, functions, construction, management and the significance in raising the quality of engineering will be done in this paper.

\section{CAMPUS ENGINEERING EDUCATION CENTER}

It is thought by Zuo Tieyiong [4] that for students, during the college years, it is difficult to study and 
train in factories for several months, they may get basic industrial knowledge by simulation and imitation, such an occasion is the campus center of engineering education. This kind of center, as the property and function, can be divided into the following types. The first may be called management type, which has its office and management team, but has not its own guidance teachers, the teaching and training are performed in various campus engineering training centers or some related enterprise. The second may be called entity type, which has its office, management team, guidance teachers, training venues and facilities, but has no relation with the student training in enterprise. The third may be called comprehensive type, which is endowed with the functions of management engineering practice whether campus or off-campus, at the same time it has its own venues, facilities and its guidance teacher team for practical education in campus. That which type of campus center of engineering education will be constructed is determined by the specific situation of engineering education in the college, and with no questions of better or more unfavorable.

\subsection{Functions of campus center of engineering education}

The function of campus center of engineering education reflects in partly achieving the target of teaching plan of engineering practice firstly. A reasonable engineering education should not only follow the rules of education, but also meet the needs of the service object, which can be implemented through the course system and professional talent training plan. It can be seen throughout the system or program that, in a college, the cultivation of engineering talents is with the aid of the classroom firstly, then of all kinds of laboratories, training centers or bases. In center of engineering education managed by the college, the content of engineering practice, ruled in course system or program, will be specified, including training in which campus center of engineering education, or in which off-campus center, when going to, and with what specified requirement. So, in fact, such a center plays the role of planning and communication, for example, students' training or practice results can be reported by the center to the administration office. The campus center of engineering education may give a few specialized courses, but more of its work is to provide specific content of the training, and at the last time, sends the result of training to related departments.

The functions of campus center of engineering education reflect in its being an important platform for cultivating young teachers and improving their ability of engineering practice secondly. Usually, campus center of engineering education is within the teaching districts, so teachers can enter and join training at any time after the classroom teaching, in which new teachers may improve their engineering practice ability, at the same time they may play the role of assistants and solve the problem of manpower shortage.

Also because of the advantage of campus center of engineering education on the opening of time and space, it provides an innovative practice platform for the teachers and students. Numbers of students, who are good at thinking and diligent in starting work, improve their ability of engineering practice and innovation rapidly through the interaction and communication with the guidance teachers in the center.

\subsection{Construction of campus center of engineering education}

Construction of campus center of engineering education includes the formation of teacher team and other conditions construction. The most important of any education platform is the formation of teacher team. When we form the team the key consideration is the personnel's professional background and his work experience, because his professionalism and engineering practice ability will directly affect the quality of work. Of course, Managers in the center also need to know the education management appropriately, and teachers also need to accept teaching skills training. In order to lay a solid foundation for the steady improvement of the quality of teaching the center needs a teacher team being good at both technology and education. At the same time, center also need to pay attention to the promotion of the team and personal development, guiding everyone to actively carry out technological innovation and academic research, which is crucial for the teacher's growth and the team's stability.

The construction funds for campus center of engineering education may come from the government, may also come from the college selfraised. It is particularly important to get the corporate sponsorship. For company that focuses on the research, development, production and promotion of some equipment and instruments are often willing to display their products in occasions such as center of engineering education. For them doing like this both supports education and cultivate the customer in the future, and is a win-win thing.

\subsection{Operation and management of campus center of engineering education}

The effective operation of campus center of engineering education depends on scientific and strict management. To establish a set of rules, both conforming the law of engineering education and considering the actual status of the college and the 
center, about the central structure of the organization and the method of teaching management is not only the software construction of center but also the powerful guarantee of center's effective operation and sustainable development.

The organizational structure of a pure management or entity center is relatively simple, the former's responsibilities is to accept the practical teaching plan from relevant departments, and to arrange specific practice bases, The latter is to accept training plan, arrange specific guidance and training content and put them into practice.

A comprehensive center is often a relatively independent teaching unit in which there exist several offices and laboratories. The function of office is approximately equivalent to that of a pure management center, and the training room is basically equivalent to a single entity type center. Of course there are differences between them, in addition to the conventional management of staff and practical teaching, Such center need to consider more about the construction of the off-campus bases, teaching staff and monitoring the teaching quality of engineering practice. At the same time paying special attention to contact and communicate with related management personnel is the first condition of ensuring the smooth implementation of teaching and training outside the college.

\section{CENTER OF ENGINEERING EDUCATION BASED ON THE ENTERPRISE}

From a functional point of view center of engineering education based on the enterprise is the center of engineering practical education. Observing from the project management and the scope of services, there are different levels of center of engineering practical education - the national and provincial. There are currently more than 600 national centers of engineering practical education across the country, the number of provincial is more, most of which are still in the construction or improvement.

Establishing center of engineering practical education in the enterprise is to create the condition for the students to carry on the enterprise learning. It is thought by Lin Jian [5] that the advantages of learning in the enterprise are the condition of engineering practice and the real engineering environment. In fact, learning in the enterprise, students can not only see the running process, equipment and control instrument, but also learn the production organization, and experience the enterprise culture.

\subsection{The property of center of engineering practical education}

Compared with the traditional off-campus practice base, the center of engineering practical education has the following several characteristics. Firstly, it serves for engineering education, can only be set up in enterprises. Secondly, it is necessary to implement the "outstanding engineers training plan". Thirdly, it is a comprehensive platform to cultivate engineering talents by the joint of college and enterprise. College-enterprise joint training means that companies no longer stay in a student internship, but involve in all the way from the formulation of plan of professional personnel training to implementation process and quality evaluation. That is to make enterprise stakeholders through the cultivation of the innovative engineering talent and technology development.

Comprehensive platform means that the center of engineering practical education is not simply a occasion for students' cognition practice, professional practice and graduation practice, but is a base with various functions needed by the engineering talent cultivation, from enterprise course learning, enterprise culture experience, to professional skills training, project research and graduation design etc. As is thought by Zhang Laibing [6], practice education is one of the philosophies, not simply means the practical teaching links such as experiment, professional practice, graduation design etc. practice education can not be completely equivalent to practice teaching, more importantly, it should be reflected in the whole process of talent training in college

\subsection{Co-construction of center of engineering practical education}

The construction of center of engineering practical education involves all teaching resources configuration during students learning stage. In the U.S., MIT established a practice institute and their idea is [7] in choosing cooperation enterprise they should adhere to the strict criteria, in cooperation the benefit of the enterprise must be ensured, at the same time the interests of enterprise, such as intellectual property rights, must be protected. From our recent practice experience, choose cooperative enterprises should pay attention to the following points.

Firstly, enterprise has the willingness to cooperate with a college. The nature of any enterprise is to pursue the maximization of profits. Now people's awareness of environmental protection and safety is growing. Some companies, especially those engaged in hazardous chemical processing and storage, metallurgy, mining, heavy manufacturing, civil bridge, are very worried about the security of students, as well as those, with high technical content, worry about technical secrets leaked out, are 
reluctant to even refused to accept students to study in their enterprises. For this type of enterprise, college, on the one hand, should strengthen the education of security and secrecy, ask teachers and students to comply with enterprise's rules and regulations strictly; on the other hand, should try to make good use of the historical relationship, such as alumni and industry background relationship, formed in the cooperation between college and enterprises, and recommend to enterprises outstanding graduates and united technologies research. So, enterprises will be willing to cooperate with the college.

Secondly, the enterprise must be a power one, the cooperative enterprise should have relatively complete staff training system and nice living facilities. In a company with perfect staff training system and nice living facilities, construction of the center will help to supplement and improve the training facilities, maintenance living facilities.

Thirdly, the cooperative enterprise should have a high level. The center of engineering practical education is a comprehensive education platform for engineering talent training, the purpose of which is to cultivate the ability of engineering practice of applied engineering talents. If a business enterprise is ill-equipped, lack of engineering and technical personnel and with management confusion, then how to build a high level engineering practice education center, how to cultivate excellent talents?

Fourthly, the closer that the enterprise to the college, the better. Engineering education itself is a kind of high cost education. If the distance from the college to the practice position is long, the limited internship funds will be spent on the trip fully. This is every person who is engaged in the management of engineering education must be taken into account.

\subsection{Operation of engineering practice education center}

For a complete engineering practice education center, to launch a set of teaching plan involving enterprise participation deeply, students' learning quality monitoring and evaluation, and teaching about security and confidentiality are essential, in addition to the construction of practical training venues, facilities, and a team of guidance teachers. Although the cost to develop measure is not big, the measure for the center administration is the basis of cooperation to cultivate talents, and is the sign of the center level. Perfect management measure is a reliable system guarantee for the center.

In a modern enterprise staffing is very limited, and the college must set up the corresponding post to take part in the management of engineering practice education center, including setting up mechanism of communication and coordination, division of labor cooperation of specific affairs involving the center operation to provide organization and management guarantee.

The teacher team of the center is made up of college teachers and enterprise ones. In training for teachers from the college, it must be focused on the improvement of engineering practice ability; and for teachers from the enterprise, it mainly on the improvement of teaching skills. In the process of carrying out the training scheme cooperatively, course teaching, training guidance, textbook compilation, and technical research, the continued convergence and continuous training of teachers from college and enterprise provide a reliable teacher guarantee for the center.

\section{CONCLUSION}

Engineering education center is the most important platform to realize the goal of engineering education. Whether for the campus center or the off-campus center, the construction and operation should be suitable to the condition of the college and to the local environment. At the same time, scientific management approach, innovation of mechanism system, abundant and reasonable structure of teaching staff will make engineering education center plays a decisive role in improving quality of engineering education and cultivating the qualified engineers talents.

\section{ACKNOWLEDGMENT}

The support from the Education Reform Project in Guangdong Province, YCJ20114731704, is gratefully acknowledged.

\section{REFERENCES}

[1] http://en.wikipedia.org/wiki/Engineering_education

[2] Cui,J. 2011. Return to the engineering practice. China's higher engineering education curriculum reform research. Ph.D. thesis of Nanjing University.

[3] China Ministry of Education. Notice about the construction of national engineering practice education center.

[4] Zuo,T.Y. \& Lin,Z.Q. 2010.Engineering practice education must be strengthened. Laboratory Research and Exploration. Vol(29):1-5

[5] Lin,J. 2013.Outstanding engineer training - engineering education systemic reform research. Beijing, Tsinghua University Press.

[6] Zhang,L. 2006. Active exploration engineering education method and the future. China's Higher Education, $\operatorname{vol}(12): 1-3 a$

[7] Gu,Z. \& Li,W. 2010. Co-operative classic mode characterized by engineering practice education - MIT institute of chemical industry practice exploration in one hundred. Higher Engineering Education Research. Vol (6):29-37 